\title{
Activin A maintains pluripotency markers and proliferative potential of human induced pluripotent stem cells
}

\author{
MINORU TOMIZAWA ${ }^{1}$, FUMINOBU SHINOZAKI ${ }^{2}$, TAKAO SUGIYAMA ${ }^{3}$, \\ SHIGENORI YAMAMOTO ${ }^{4}$, MAKOTO SUEISHI $^{3}$ and TAKANOBU YOSHIDA ${ }^{5}$ \\ Departments of ${ }^{1}$ Gastroenterology, ${ }^{2}$ Radiology, ${ }^{3}$ Rheumatology, ${ }^{4}$ Pediatrics, and ${ }^{5}$ Internal Medicine, \\ National Hospital Organization Shimoshizu Hospital, Yotsukaido, Chiba 284-0003, Japan
}

Received December 7, 2010; Accepted February 7, 2011

DOI: $10.3892 / \mathrm{etm} .2011 .219$

\begin{abstract}
To investigate the role of Activin A in the embryoid bodies (EBs) of human induced pluripotent stem (iPS) cells, EBs were transferred onto dishes coated with Matrigel after 4 days of incubation with Activin A and observed under a microscope. Alkaline phosphatase staining and immunostaining were performed to analyze the pluripotency of the cells, and the MTS assay was performed to analyze their proliferative potential. Fourteen days after EB formation, cells cultured with Activin A (100 ng/ml) showed no morphological alterations. Cells cultured with 10-100 ng/ml of Activin A were positive for alkaline phosphatase staining, while cells cultured with $0-3 \mathrm{ng} / \mathrm{ml}$ showed negative staining. Cells cultured with $10 \mathrm{ng} / \mathrm{ml}$ of Activin A were positive for Oct $3 / 4$, Nanog, SSEA-4 and TRA-1-60, while cells cultured with $0 \mathrm{ng} / \mathrm{ml}$ Activin A were negative. Cells cultured with $3-30 \mathrm{ng} / \mathrm{ml}$ of Activin A maintained their proliferative potential, while loss of proliferative potential was observed in cells cultured with $100 \mathrm{ng} / \mathrm{ml}$ Activin A. In conclusion, Activin A maintained pluripotency markers in human iPS cells cultured as EBs with Activin A.
\end{abstract}

\section{Introduction}

Activin A, a member of the transforming growth factor- $\beta$ superfamily, mimics Nodal, binds Activin receptors and phosphorylates Smad2, thus activating it (1). Once activated, Smad2 associates with Smad4, translocates to the nucleus and regulates gene expression in conjuction with other transcription factors. Nodal/Activin A signals play a crucial role in inducing the development of the mesoderm and endoderm in the Xenopus embryo $(2,3)$.

Activin A $(100 \mathrm{ng} / \mathrm{ml})$ promotes the differentiation of human embryonic stem (ES) cells into pancreatic $\beta$ cells (4),

Correspondence to: Dr Minoru Tomizawa, Department of Gastroenterology, National Hospital Organization Shimoshizu Hospital, 934-5 Shikawatashi, Yotsukaido, Chiba 284-0003, Japan E-mail: nihminor-cib@umin.ac.jp

Key words: embryoid body, alkaline phosphatase staining, feederfree culture and also into endoderm (5). By contrast, $5 \mathrm{ng} / \mathrm{ml}$ of Activin A was found to maintain self-renewal and to support the longterm feeder-free culture of human ES cells (6). However, it has not been fully established whether Activin A induces the differentiation of human ES cells into endoderm or maintains them in an undifferentiated state. Curiously, 100 $\mathrm{ng} / \mathrm{ml}$ of Activin A, FGF-2 and BMP-4 was found to induce the expression of endoderm markers, while still maintaining pluripotency markers such as Oct3/4 and Nanog (7). These data suggest that a mixture of other growth factors or the specific concentration of Activin A may determine whether human ES cells differentiate or whether their pluripotency is maintained. To develop a feeder-free medium of human ES or induced pluripotent stem (iPS) cells, it is necessary to determine the appropriate concentration of Activin A.

\section{Materials and methods}

Cell culture and embryoid body formation. The human iPS cell line 201B7 (Riken Cell Bank, Tsukuba, Japan) was cultured in ReproFF media (Reprocell, Yokohama, Japan) for feeder-free culture (Reprocell, Tokyo, Japan) on dishes (Asahi Techno Glass, Funabashi, Japan) coated with Matrigel (Becton Dickinson, Franklin Lakes, NJ, USA) in 5\% carbon dioxide at $37^{\circ} \mathrm{C}$ in a humidified chamber, and harvested with Accutase (Innovative Cell Technologies, Inc., San Diego, CA, USA) for subsequent experiments. Dissociated 201B7 cells were cultured in hanging drops at a density of 1,000 cells per $30 \mu \mathrm{l}$ of medium composed of Dulbecco's minimum essential medium-F12 medium (Sigma Aldrich Japan K.K., Tokyo, Japan) supplemented with 20\% knockout serum replacement (KSR) (Invitrogen Japan K.K., Tokyo, Japan), $10 \%$ minimum essential amino acids (Invitrogen Japan K.K.), $2 \mathrm{mM}$ L-glutamine (Invitrogen Japan K.K.) and $1 \mathrm{mM}$ 2-mecaptoethanol (Sigma Aldrich Japan K.K.) [iPSm(-)] (8). After 4 days of hanging drop culture, the resulting embryoid bodies (EBs) were plated onto plastic dishes coated with Matrigel. Cells were observed under an Olympus IMT-2 microscope (Olympus, Tokyo, Japan).

Alkaline phosphatase staining. Alkaline phosphatase (ALP) staining was carried out in cells cultured on a 6-well plate (Asahi Techno Glass) coated with Matrigel. Alkaline phos- 


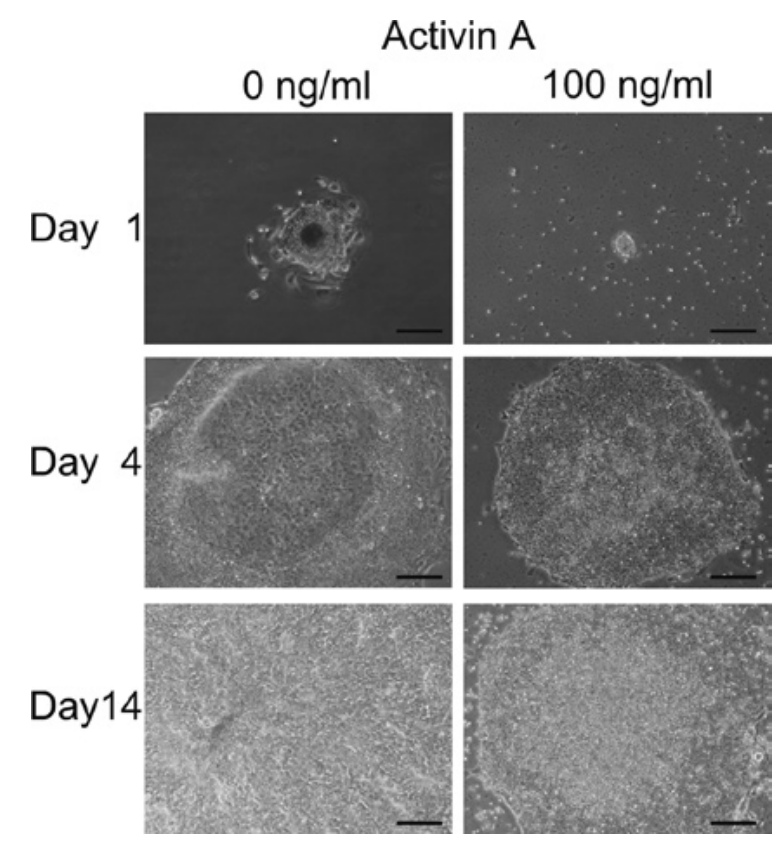

Figure 1. Activin A maintains iPS cells in an undifferentiated state. Embryoid bodies (EBs) were formed with a hanging drop method. Four days after being plated onto dishes coated with Matrigel, cells in EBs cultured without Activin A were differentiated. In contrast, those cultured with $100 \mathrm{ng} / \mathrm{ml}$ Activin A remained undifferentiated up to 14 days after plating. Original magnification, $\mathrm{x} 40$; scale bar, $500 \mu \mathrm{m}$.

phatase staining was performed with leukocyte alkaline phosphatase (Sigma Aldrich Japan K.K.) according to the manufacturer's instructions.

Immunostaining. Cells cultured on 4-well chamber slides (Becton Dickinson) were fixed in $4 \%$ paraformaldehyde (Sigma Aldrich Japan K.K.) and incubated with hydrogen oxide in $100 \%$ methanol for $30 \mathrm{~min}$ at $4^{\circ} \mathrm{C}$. Specimens were incubated with $2 \%$ fetal bovine serum in PBS (wash buffer) for $30 \mathrm{~min}$ at $4^{\circ} \mathrm{C}$. For the anti-Oct $3 / 4$ (Becton Dickinson) and anti-Nanog (Reprocell) antibodies, specimens were incubated in $0.1 \%$ sodium citrate (Wako Pure Chemicals, Osaka, Japan) and $0.1 \%$ Triton X-100 (Wako Pure Chemicals) in distilled water. Diluted (1:500) anti-Oct3/4, anti-Nanog, anti-SSEA-4 and anti-TRA-1-60 antibodies (all from Nihon Millipore K.K., Tokyo, Japan) were incubated in wash buffer overnight at $4^{\circ} \mathrm{C}$. After washing three times with PBS, diluted 1:500 horseradish peroxidase-labeled anti-mouse (GE Healthcare Japan, Tokyo, Japan) or anti-rabbit (GE Healthcare Japan) antibodies were incubated in wash buffer for $3 \mathrm{~h}$ at $4^{\circ} \mathrm{C}$. Diaminobenzidine (Dako Japan, Tokyo, Japan) was applied, and the nuclei were stained with hematoxylin (Muto Pure Chemicals Co., Ltd., Tokyo, Japan) for $15 \mathrm{sec}$. Specimens were observed and photographed under an Olympus AX80 microscope (Olympus).

Cell proliferation assay. Cells were seeded onto a 96-well plate (Asahi Techno Glass) coated with Matrigel at a density of 1,000 cells/well. Twenty-four hours later, the medium was replaced with Activin A (R\&D Systems Inc., Minneapolis, MN, USA). Seventy-two hours later, the 3-(4,5-dimethylthiazol-2-yl)-5-(3-carboxymethoxyphenyl)2-(4-sulfophenyl)-2H-tetrazolium inner salt (MTS) assay

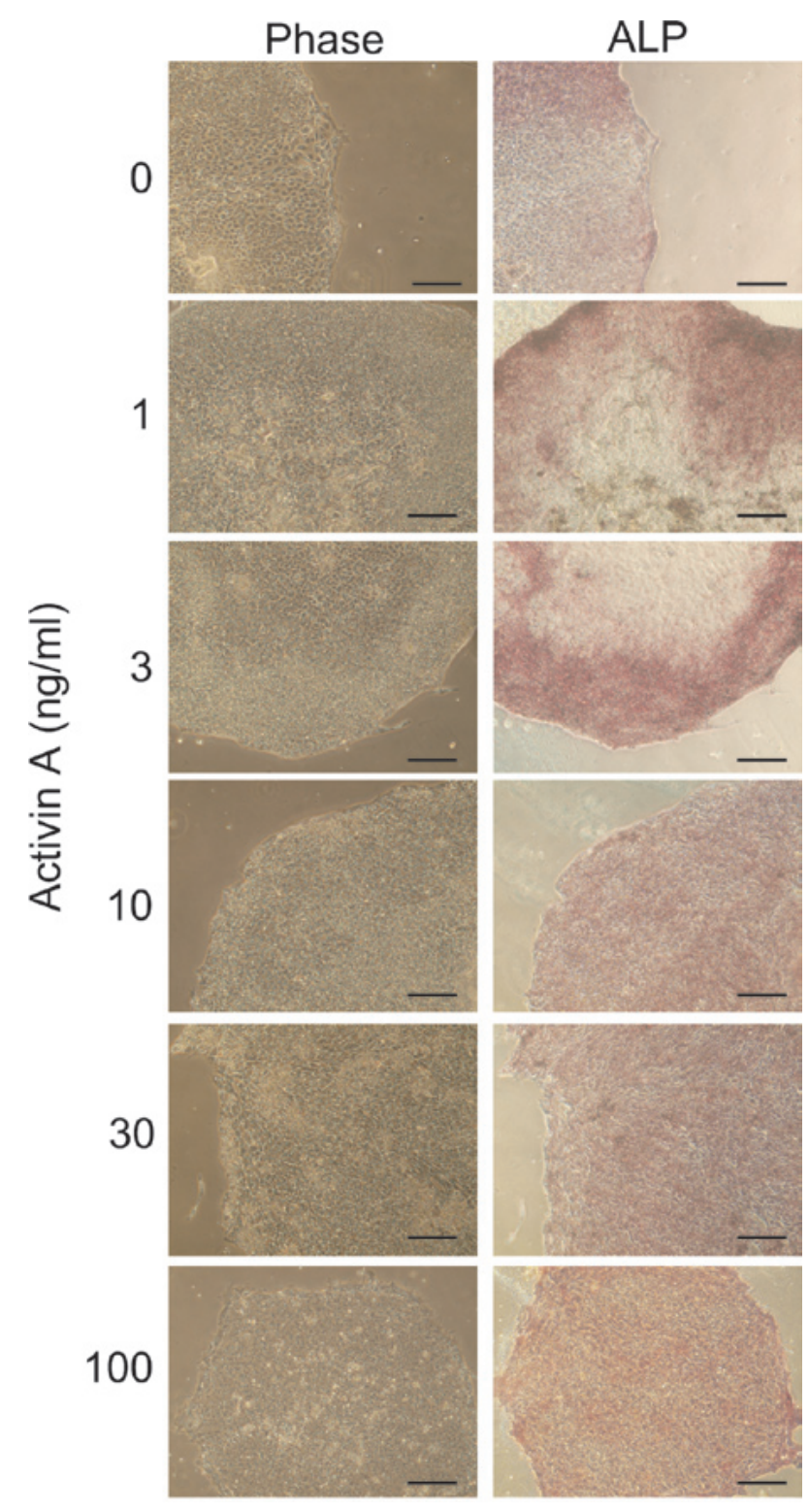

Figure 2. Alkaline phosphatase (ALP) staining. Fourteen days after the formation of embryoid bodies (EBs) with Activin A, ALP staining was performed. EBs were positively stained in the presence of $>10 \mathrm{ng} / \mathrm{ml}$ of Activin A. Phase, phase contrast without ALP staining; ALP, phase contrast with ALP staining. Original magnification, $\mathrm{x} 40$; scale bar, $500 \mu \mathrm{m}$.

was performed according to the manufacturer's instructions (Promega Corporation, Tokyo, Japan). MTS was bio-reduced by cells into a colored formazan product that reduces absorbance at $490 \mathrm{~nm}$. The absorbance was analyzed at a wavelength of $490 \mathrm{~nm}$ with a Bio-Rad iMark microplate reader (Bio-Rad, Hercules, CA, USA).

\section{Results}

Initially, we aimed to promote the differentiation of iPS cells to hepatocytes with EB formation using $100 \mathrm{ng} / \mathrm{ml}$ of Activin A (9). Four days after the transfer of EBs to 6-well plates, differentiated cells appeared in the center of the colonies cultured with $0 \mathrm{ng} / \mathrm{ml}$ of Activin A, while no morphological change was noted in cells cultured with $100 \mathrm{ng} / \mathrm{ml}$ of Activin A (Fig. 1). Fourteen days later, all cells cultured with $0 \mathrm{ng} / \mathrm{ml}$ 


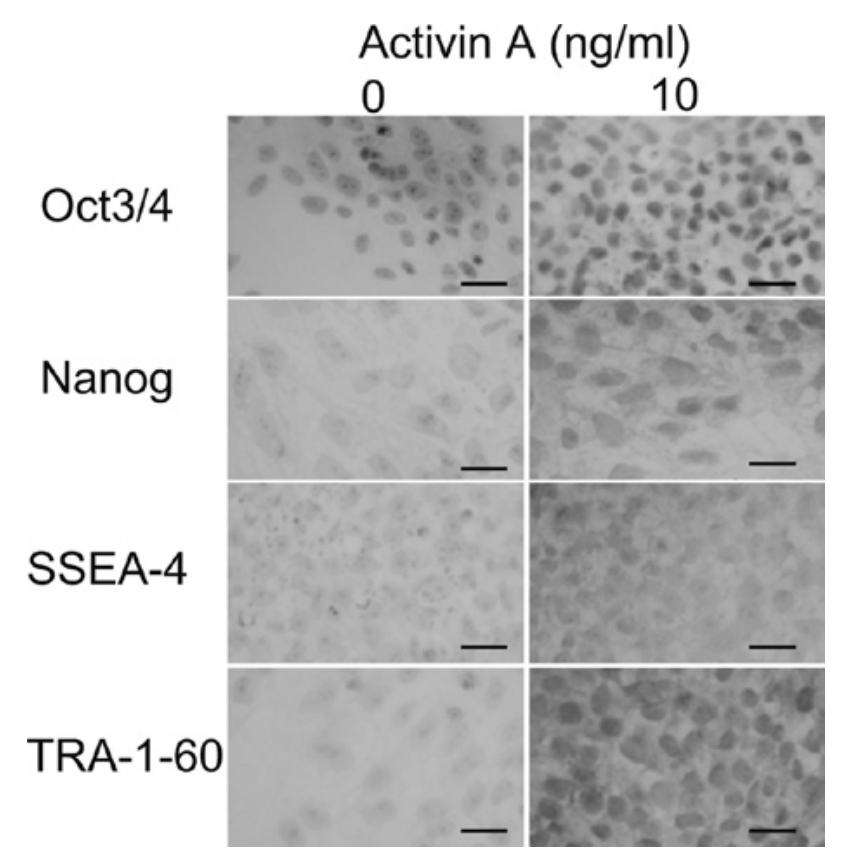

Figure 3. Immunostaining. Fourteen days after embryoid body (EB) formation, cells were subjected to immunostaining with Oct3/4, Nanog, SSEA-4 and TRA-1-60 antibodies. Cells cultured without Activin A were negative for all of the antibodies, while cells were positive when cultured with $10 \mathrm{ng} /$ $\mathrm{ml}$ of Activin A. Original magnification, $\mathrm{x} 400$; scale bar, $50 \mu \mathrm{m}$.

of Activin A were differentiated, while cells cultured with $100 \mathrm{ng} / \mathrm{ml}$ remained undifferentiated. These data indicate that Activin A maintained iPS cells in an undifferentiated state. It appeared that colonies grew more slowly when cultured with $100 \mathrm{ng} / \mathrm{ml}$ than with $0 \mathrm{ng} / \mathrm{ml}$ Activin A.

To determine whether the cells maintained an undifferentiated state after 14 days of culture in Activin A, ALP staining was performed. Cell cultured in $>10 \mathrm{ng} / \mathrm{ml}$ of Activin A were positive for ALP staining (Fig. 2). In contrast, most of the cells cultured in $<3 \mathrm{ng} / \mathrm{ml}$ of Activin A were negative for ALP staining. This suggests that $10 \mathrm{ng} /$ $\mathrm{ml}$ of Activin A was sufficient to maintain the cells in an undifferentiated state.

To confirm that the cells remained undifferentiated at $10 \mathrm{ng} / \mathrm{ml}$ of Activin A, immunostaining was performed. All cells cultured in $10 \mathrm{ng} / \mathrm{ml}$ of Activin A demonstrated positive nuclear staining for Oct3/4 and Nanog (Fig. 3). None of the cells in the absence of Activin A were positive for Oct $3 / 4$ or Nanog. The cell surfaces of all of the cells cultured in $10 \mathrm{ng} /$ $\mathrm{ml}$ Activin A were positive for SSEA-4 and TRA-1-60, while none were positive in the absence of Activin A. These results suggest that $10 \mathrm{ng} / \mathrm{ml}$ of Activin A maintains cells in an undifferentiated state.

Fig. 1 indicates that cells cultured with $100 \mathrm{ng} / \mathrm{ml}$ of Activin A exhibited weaker proliferation than those cultured in $0 \mathrm{ng} / \mathrm{ml}$. The MTS assay was performed to analyze the effects of Activin A on the proliferative potential of the cells, and revealed a proliferation of $>100 \%$ in cells cultured with 3-30 ng/ml of Activin A, and of $85.5 \%$ at $100 \mathrm{ng} / \mathrm{ml}$, compared to cells treated with $0 \mathrm{ng} / \mathrm{ml}$ (Fig. 4). This demonstrated that Activin A promotes cell proliferation at a concentration of 3-30 ng/ml, while a concentration of $100 \mathrm{ng} / \mathrm{ml}$ suppresses cell proliferation.

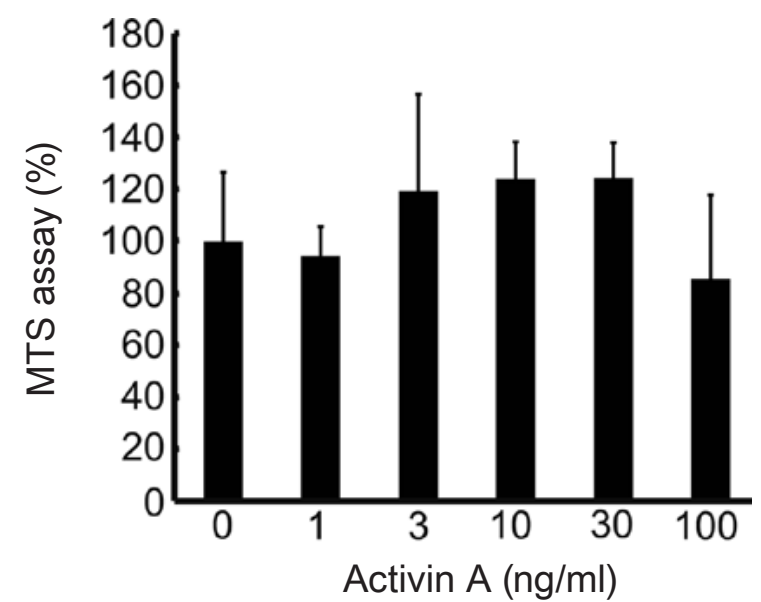

Figure 4. Cell proliferation assay of 201B7 cells cultured with Activin A. Stimulation of cell proliferation by Activin A was analyzed by the MTS assay. Activin A (3-30 ng/ml) stimulated the proliferation of $201 \mathrm{~B} 7$ cells. At $100 \mathrm{ng} / \mathrm{ml}$, cell proliferation was lower than that of $0 \mathrm{ng} / \mathrm{ml}$ of Activin A.

\section{Discussion}

Activin A (10 ng/ml) and FGF2 (12 ng/ml) maintain the pluripotency of human iPS cells in a feeder-free condition (10). Cultured human iPS cells form teratoma when transplanted into the testis capsule of severe combined immunodeficientbeife mice after 20 passages. In our experiments, $100 \mathrm{ng} / \mathrm{ml}$ of Activin A alone was added to the medium, since our initial goal was to develop a method of differentiating human iPS cells to hepatocytes. Unexpectedly, the cultured cells via EBs showed no morphological changes after 14 days of EB formation. Beattie et al obtained similar results when culturing human ES cells (HSF6) in media with several cocktails of growth factors (11). They found that a combination of Activin A (50 ng/ml), nicotinamide $(10 \mathrm{mM})$ and keratinocyte growth factor $(50 \mathrm{ng} /$ ml) was sufficient to preserve the pluripotency of human ES cells. Our data clearly indicate that Activin A alone is capable of maintaining pluripotency markers in human iPS cells, as evidenced by ALP staining and immunostaining. Previously, the proliferation of human ES cells was found to be reduced and the passage of cells was halted by Actin A (11). Xiao et al succeeded in the long-term feeder-free culture of human ES cells (H1) for a time period longer than 150 days and 20 passages with $5 \mathrm{ng} / \mathrm{ml}$ of Activin A (6). The differences in results between the two previous reports may be attributed to the cell lines and concentrations of Activin A used. In certain cell lines, activation of another pathway may be necessary, since the Wnt pathway preserves the pluripotency of human ES cells (12). Xiao et al applied a lower concentration of Activin A for a successful long-term passage. Our MTS assay showed that human iPS cells exhibited a weaker proliferative potential when cultured in $100 \mathrm{ng} / \mathrm{ml}$ of Activin A compared to $0 \mathrm{ng} / \mathrm{ml}$. Moreover, $3-30 \mathrm{ng} / \mathrm{ml}$ of Activin A was suitable for human iPS cell proliferation compared to $0 \mathrm{ng} / \mathrm{ml}$. Our data and previous reports suggest that a lower concentration of Activin A is appropriate for human ES and iPS cells to maintain not only pluripotency markers, but also proliferative potential.

Activin A (25 ng/ml) was found to increase the expression of Oct3/4 and Nanog in human ES cells with pluripotency 
when added in chemically defined medium (13). When the medium was deprived of Activin A, the expression of Nanog was down-regulated (14). These reports verify that Activin A controls the expression of Oct3/4 and Nanog to maintain pluripotency.

Sulzbacher et al hypothesized that the pluripotency or differentiation of cells is dependent and occurs in a concentration- and stage-dependent manner (1). Activin A (5-50 ng/ml) was applied to maintain the pluripotency of human ES and iPS cells alone or with other growth factors $(6,10,11,15)$. In the present study, as in the study of Xiao et al, 5 and $10 \mathrm{ng} /$ $\mathrm{ml}$ of Activin A, respectively, were applied as a sole growth factor to maintain pluripotency. These data suggest that a lower concentration of Activin A maintains the pluripotency of human ES or iPS cells. Conversely, human ES (H9) cells were found to differentiate with FGF2 or Activin A $(10 \mathrm{ng} / \mathrm{ml})$ alone after three passages, and a combination of Activin A + FGF2 or Nodal + FGF2 was found to be optimal for the long-term expression of pluripotency markers (15). One may speculate that $\mathrm{H} 9$ cells require FGF2 in addition to Activin A. Whether Activin A is enough to maintain pluripotency or requires other growth factors may depend on the cell line.

To induce mesoendodermal differentiation, the optimal combination was found to consist of BMP4 (10 ng/ml), FGF2 (20 ng/ml), LY294002 $(10 \mu \mathrm{M})$ and a higher concentration of Activin A (100 ng/ml) (10). These data indicate that a combination of growth factors and a higher concentration of Activin A is necessary for human ES or iPS cells to differentiate. Notably, Activin A (100 ng/ml), FGF-2 and BMP-4 induce the expression of endoderm markers, while still maintaining pluripotency markers such as Oct3/4 and Nanog (7). This may explain our finding that $100 \mathrm{ng} / \mathrm{ml}$ of Activin A maintained pluripotency markers, while other researchers noted differentiation at this high concentration.

Our next study will carry out the passage and long-term culture of human iPS cells in Activin A while analyzing the undifferentiated state.

\section{Acknowledgements}

This study was supported in part by a Grant-in-Aid for the Encouragement of Scientists from the Japan Society for the Promotion of Science (JSPS) (no. 22931047). The authors thank Dr Masaki Takiguchi and Dr Katsuro Iwase for the technical assistance and fruitful discussions.

\section{References}

1. Sulzbacher S, Schroeder IS, Truong TT and Wobus AM Activin A-induced differentiation of embryonic stem cells into endoderm and pancreatic progenitors - the influence of differentiation factors and culture conditions. Stem Cell Rev 5: 159-173, 2009.

2. Smith JC, Price BM, van Nimmen K and Huylebroeck D: Identification of a potent Xenopus mesoderm-inducing factor as a homologue of Activin A. Nature 345: 729-731, 1990.

3. Thomsen G, Woolf T, Whitman M, et al: Activins are expressed early in Xenopus embryogenesis and can induce axial mesoderm and anterior structures. Cell 63: 485-493, 1990.

4. D'Amour KA, Agulnick AD, Eliazer S, Kelly OG, Kroon E and Baetge EE: Efficient differentiation of human embryonic stem cells to definitive endoderm. Nat Biotechnol 23: 1534-1541, 2005.

5. Yao S, Chen S, Clark J, et al: Long-term self-renewal and directed differentiation of human embryonic stem cells in chemically defined conditions. Proc Natl Acad Sci USA 103: 6907-6912, 2006.

6. Xiao L, Yuan X and Sharkis SJ: Activin A maintains selfrenewal and regulates fibroblast growth factor, Wnt, and bone morphogenic protein pathways in human embryonic stem cells. Stem Cells 24: 1476-1486, 2006.

7. Touboul T, Hannan NR, Corbineau S, et al: Generation of functional hepatocytes from human embryonic stem cells under chemically defined conditions that recapitulate liver development. Hepatology 51: 1754-1765, 2010.

8. Tomizawa M, Toyama Y, Ito C, et al: Hepatoblast-like cells enriched from mouse embryonic stem cells in medium without glucose, pyruvate, arginine, and tyrosine. Cell Tissue Res 333: 17-27, 2008.

9. Basma H, Soto-Gutierrez A, Yannam GR, et al: Differentiation and transplantation of human embryonic stem cell-derived hepatocytes. Gastroenterology 136: 990-999, 2009.

10. Vallier L, Touboul T, Brown S, et al: Signaling pathways controlling pluripotency and early cell fate decisions of human induced pluripotent stem cells. Stem Cells 27: 2655-2666, 2009.

11. Beattie GM, Lopez AD, Bucay N, et al: Activin A maintains pluripotency of human embryonic stem cells in the absence of feeder layers. Stem Cells 23: 489-495, 2005.

12. Sato N, Meijer L, Skaltsounis L, Greengard $P$ and Hemmati-Brivanlou A: Maintenance of pluripotency in human and mouse embryonic stem cells through activation of Wnt signaling by a pharmacological GSK-3-specific inhibitor. Nat Med 10: 55-63, 2004.

13. James D, Levine AJ, Besser D and Hemmati-Brivanlou A: TGFbeta/activin/nodal signaling is necessary for the maintenance of pluripotency in human embryonic stem cells. Development 132: 1273-1282, 2005.

14. Vallier L, Mendjan S, Brown S, et al: Activin/Nodal signalling maintains pluripotency by controlling Nanog expression. Development 136: 1339-1349, 2009.

15. Vallier L, Alexander M and Pedersen RA: Activin/Nodal and FGF pathways cooperate to maintain pluripotency of human embryonic stem cells. J Cell Sci 118: 4495-4509, 2005. 